\title{
Histomorphometric and Histological Evaluations of the Flaxseeds Effect on Dentin Formation in Offsprings' Teeth of Diabetic and Non-Diabetic Pregnant Rats
}

\author{
Nancy Mamdouh Saad ${ }^{1, *}$, Nawal A. El Masri ${ }^{2}$, Fathy Ibrahim Shehata ${ }^{2}$, Sahar Shafik ${ }^{2}$, \\ Mounir Mahmoud El Adawy ${ }^{3}$ \\ ${ }^{1}$ MSc, Bds \\ ${ }^{2}$ Professor of Oral Biology, Faculty of Dentistry, Alexandria University \\ ${ }^{3}$ Professor of Animal Nutrition, Faculty of Agriculture, Alexandria University \\ Corresponding author: nancy_tourky@yahoo.com
}

Received October 12, 2014; Revised November 23, 2014; Accepted December 21, 2014

\begin{abstract}
Omega-3\&6 fatty acids and their derivatives are so essential to a child's development. A well-nourished nursing mother provides her infant with a perfect blend of essential fatty acids flaxseeds and their long-chained derivatives, assuring the body tissues a rich supply. Several factors affecting eruption dates ranging from root development, nutrition, chronic diseases, rich tissue vascularity and hormonal influences have been implicated in this process. Gestational diabetes can have severe adverse effects on fetal and neonatal developmental outcomes. The present study provide the first evidence on the effect of flaxseeds as a source of omega 3 \& 6 on offsprings' tooth development with compromised pregnancy.
\end{abstract}

Keywords: flaxseeds, omega-3, eruption date, diabetes, pregnancy

Cite This Article: Nancy Mamdouh Saad, Nawal A. El Masri, Fathy Ibrahim Shehata, Sahar Shafik, and Mounir Mahmoud El Adawy, "Histomorphometric and Histological Evaluations of the Flaxseeds Effect on Dentin Formation in Offsprings' Teeth of Diabetic and Non-Diabetic Pregnant Rats.” International Journal of Dental Sciences and Research, vol. 2, no. 6C (2014): 1-7. doi: 10.12691/ijdsr-2-6C-1.

\section{Introduction}

Development and growth are extremely complex processes, involving well-coordinated sequences of metabolic events. The process of tooth development is a complicated multifactorial one; it is a part of general development and growth. Although genetic factors play a role in specifying the general limits of growth, a number of environmental factors, including nutrition, are important in the ultimate outcome of development. [1] Nutrition has a profound influence on oral tissues, both during their development, growth and their functional integrity. Hence, all life support systems of both mother and child during pregnancy and lactation will be affected by the quality of food intake and their health condition. After birth nutrition will continue to be of vital importance through their lifetimes [2].

People with fasting glucose levels from 110 to 125 $\mathrm{mg} / \mathrm{dl}$ (6.1 to $6.9 \mathrm{mmol} / \mathrm{l})$ are on the other hand tooth development or odontogenesis is the complex process by which teeth form from embryonic cells, grow, and erupt into the oral cavity, it is initiated by signals from the epithelial dental lamina to the ectomesenchyme. [3,4] The process of a dental development occurs over a significant amount of time in an individual's life. Primary teeth start to form between the sixth and eighth weeks, and permanent teeth begin to form later in the twentieth weeks.
The basic developmental process is similar for all teeth but each tooth developed as an anatomically distinct unit. [5,6] considered to have impaired fasting glucose.(7) Patients with plasma glucose at or above $140 \mathrm{mg} / \mathrm{dL}(7.8$ $\mathrm{mmol} / \mathrm{L}$ ), but not over $200 \mathrm{mg} / \mathrm{dL}(11.1 \mathrm{mmol} / \mathrm{L})$, two hours after a $75 \mathrm{~g}$ oral glucose load are considered to have impaired glucose tolerance. Of these two prediabetic states, the latter in particular is a major risk factor for progression to full-blown diabetes mellitus, as well as cardiovascular disease [8].

Gestational diabetes mellitus (GDM) is defined as glucose intolerance of various degrees that is first detected during pregnancy. It resembles type 2 diabetes in several respects. Pregnancy has long been recognized as a state of relative insulin resistance, and those women who cannot meet the increased demands for insulin during pregnancy have been labeled as having gestational diabetes mellitus (GDM). [9] It occurs in about $2 \%-5 \%$ of all pregnancies and may improve or disappear after delivery. Gestational diabetes is fully treatable, but requires careful medical supervision throughout the pregnancy. [10] Known risk factors for GDM are Age (older than 25 years; the risk is even greater after age 35, Race (occurs more often in African Americans, Hispanics, American Indians, and Asian Americans) Overweight and obesity Personal medical history of gestational diabetes, prediabetes, or previously delivering a baby weighing more than 9 pounds and Family history of type 2 diabetes (in parents 
or siblings) $[9,11]$. It has been known that diabetes that occurs during pregnancy can have severe adverse effects on fetal and neonatal outcomes. [12] The degree of glucose intolerance during pregnancy was related to the risk of developing diabetes after pregnancy. [13] Though it may be transient, untreated gestational diabetes can damage the health of the fetus or mother. Risks to the baby include macrosomia, congenital cardiac and central nervous system anomalies, skeletal muscle malformations; GDM increases the risk of premature delivery and preeclampsia. In severe cases, perinatal death may occur.(14)Nutrition intervention for women with gestational diabetes mellitus (GDM) has been recognized as the cornerstone of therapy at all stages. $[15,16]$ Dietary intake is foundational to optimal pregnancy outcomes because nutritional quality and quantity have an impact on the overall growth and development of the fetus. [17] Because, medical nutrition therapy (MNT) is the primary therapy for 30-90\% of women diagnosed with GDM, the challenge for MNT for GDM is to balance the needs of a healthy pregnancy with the need to control glucose level. $[18,19]$ Physical activity is an obvious adjunct therapy to MNT for women with GDM. It improve blood glucose control, reduce insulin resistance, reduce cardiovascular risk factors, contribute to weight control, and improve well-being. [20] Diabetes prevention trials using exercise and weight reduction have shown a $56 \%$ decrease in the incidence of diabetes in a population of people with impaired glucose tolerance. [21,22] Therefore, it is reasonable to consider that regular exercise may prevent GDM. Women who participated in any physical activity before and during pregnancy experienced a 69\% reduced risk of GDM [23] The food plan should be individualized, culturally appropriate and provided by a qualified individual with experience in GDM management as a frontline strategy for controlling gestational diabetes [24].

Essential fatty acids (EFA's) are long-chain polyunsaturated fatty acids that are necessary for normal biological activities. They are an essential dietary nutrient, as are vitamins, minerals, and amino acids (protein). [25] The EFA's are omega 3 and omega 6 fatty acids which cannot by synthesized by human body, but instead must be consumed in their diet. [26,27] These fatty acids are essential to the formation of new tissues, which occurs at an elevated rate during pregnancy and fetal development. $[28,29]$ Flaxseed is high in polyunsaturated fatty acids (73\%), moderate in monounsaturated fatty acids (18\%), and low in saturated fatty acids (9\%). Flaxseed is a rich plant source of alpha-linolenic acid (ALA), an essential fatty acid in the human diet and the parent fatty acid of the omega-3 family. [30] ALA is converted to two main longchain fatty acids, eicosapentaenoic acid (EPA) and docosahexaenoic acid (DHA), in a series of enzymatic reactions. [31] ALA has been shown to modulate eicosanoid synthesis, [32] its concentration in breast milk exceeds that of DHA, suggesting a particular requirement for ALA by infants. [33,34] Studies have shown that flax seeds may lower cholesterol levels, although with differing results in terms of gender. [35] Flax may also lessen the severity of diabetes by stabilizing blood-sugar levels. [36] EFAs also have antibacterial actions [37].

\section{Materials and Methods}

A total of sixteen males \& thirty two females' healthy albino rats of seven weeks old, with an average initial body weight $225 \pm 25$ grams were used in the present study. The rats were allotted at random in which each every two females were housed with one male for nearly one week. When the females were recognized to be pregnant by palpation and by sharp weight gain, they were separated. The pregnant rats were individually caged in metal galvanized cages under the same managerial conditions in well ventilated block building. Fresh water was automatically available all the time by stainless steel nipples for each cage. A basal diet (control, BD) was formulated to cover all essential nutrients requirement for pregnant rats according to AIN-93G diet to meet the nutritional needs of developing and lactating rats. [37] A $10 \%$ FS diet (the experimental diet, FSD) was prepared by supplementing the basal diet with $10 \%$ (w/w) ground flaxseed (IMTENAN heath shop for healthy and functional food; Organic Flax Seeds, rich source of omega 3 \& 6 Egypt) after adjustment for total calories, macronutrients, and fiber contributed by the added flaxseed. [38] The basal and experimental diets were nearly iso-nitrogenous, iso-caloric and contained similar levels of macro-elements. Throughout the experimental periods, the basal and the experimental diets were offered for the pregnant rats ad libitum in pelleted form to ensure that the pregnant females had taken all administrated supplements without selection. The experimental period were extended for seven weeks. The day of birth was designed as day one. Within 24 hours after parturition the offspring's were reduced to six, to make the stress upon lactating mothers more uniform and to provide a nearly equal opportunity to individual offspring. The same experimental diet for each group was continued throughout lactation period.

Weaning always take place after 21 days from delivery, hence all offspring in control and experimental litters were weaned at 21 days of age. Fresh diets were stored at $4^{\circ} \mathrm{C}$ and intake was monitored throughout the study period.

Table 1.

\begin{tabular}{|c|c|c|}
\hline \multirow{2}{*}{ Ingredients \% } & \multicolumn{2}{|c|}{ Experimental diets } \\
\hline & Control (BD) & Flaxseed diet(FSD) \\
\hline Egyptian berseem hay & 9.0 & 9.0 \\
\hline Bean straw & 17.5 & 14.5 \\
\hline Gluten & 16.0 & 12.0 \\
\hline Flaxseed & - & 10.0 \\
\hline Yellow corn & 15.0 & 15.0 \\
\hline Wheat bran & 18.0 & 15.0 \\
\hline Barley grain & 15.0 & 15.0 \\
\hline Soybean meal (44\%) & 3.0 & 3.0 \\
\hline Molasses & 3.0 & 3.0 \\
\hline Common salt & 1.0 & 1.0 \\
\hline Limestone & 1.0 & 1.0 \\
\hline Dicalcium phosphate & 1.0 & 1.0 \\
\hline Vitamin \& mineral premix* & 0.2 & 0.2 \\
\hline Mineral mixture & 0.3 & 0.3 \\
\hline Total & 100 & 100 \\
\hline \multicolumn{3}{|l|}{ Chemical composition (\%) } \\
\hline Dry matter & 90.46 & 90.86 \\
\hline \multicolumn{3}{|l|}{ OM basis (\%): } \\
\hline Organic matter & 90.81 & 89.96 \\
\hline Crude protein & 18.64 & 18.85 \\
\hline Ether extract & 4.21 & 4.43 \\
\hline Crude fiber & 11.42 & 11.31 \\
\hline Nitrogen free extract & 56.54 & 55.37 \\
\hline Ash & 9.19 & 10.04 \\
\hline
\end{tabular}


The composition and chemical analysis of the control diet is summarized in Table 1 . A commercial vitamin and mineral premix was added for all diet.

Vitamins and mineral premix per kilogram contained: Vit. A 2,000,000 I $\mu$, Vit. D3 150,000 l $\mu$, Vit. K 0.33 mg, Vit. B1 0.33 g, Vit B2 1.0 g, Vit B6 0.33 g, Vit. B12 1.7 mg, Panthonicacid 3.33 g, Biotin 33 m, Folic acid 0.83 g, Choline chloride 200 mg, Zn 11.7 g, Mn 5.0 g, Fe 12.5 g, Mg 66.7 mg, Se 16.6 mg, Co 1.33 mg, Cu 0.5 g, I 16.6 mg and Antioxidant $10.0 \mathrm{~g}$. Chemical composition of the control diet, faeces and urine were analyzed according to A.O.A.C. (1990).

Pregnant females were divided equally (eight in each group) as follows; Group I: Pregnant females fed with basal diet (BD). Group II: Pregnant females fed with basal diet enriched with flax seeds (FSD). Group III: Pregnant females with induced diabetes and fed with basal diet (BD). Group IV: Pregnant females with induced diabetes and fed with basal diet enriched with flax seeds (FSD).

\subsection{Induction of Diabetes}

For group I and II, the rats were injected with vehicle (citrate buffer) to simulate the influence of injection stress or buffer-induced effects on the animals. [39] For groups III and IV, the rats were fasted overnight and diabetes were induced by a single intravenous injection of Streptozotocin $60 \mathrm{mg} / \mathrm{kg}$ body weight in $0.1 \mathrm{M}$ citrate buffer. [40] Streptozotocin (STZ) was freshly prepared immediately before injection, and it was kept in cold store and refrigerator temperature $\left(2-8^{\circ} \mathrm{C}\right)$ away from light. If it is not used fresh, Streptozotocin (STZ) solution can exhibit reduced ability to induce diabetes [41].

\subsection{Measurement of Blood Glucose Level}

Blood glucose level of the animals was measured 48 hours after the administration of Streptozotocin then every two weeks throughout the time of the experiment. Blood sample were obtained from the tail vein of the animals and their blood glucose level were determined in mg/dl using a digital glucometer (Accu-chek. Advantage. Roche Diagnostic. Germany) [42].

\subsection{Histological Examination [43]}

For the light microscopic examination, mandibles were dissected out and subjected for laboratory procedure. The serial sections of each specimen were then stained with Hematoxylin and Eosin stain.

\subsection{Histomorphometric Evaluation of the Histological Slides}

Histological sections were examined by using Leica Qwin 500 image analyzer computer system. The image analyzer consisted of a colored monitor hard disc of IBM personal computer connected to the microscope, and controlled by lecicaQwin 500 software. The image of each slide of all groups were captured using x10 objective lens (Barr $=200 \mu \mathrm{m})$ with numerical aperture of a high resolution (16 bit digital camera, 1280x1024 pixel). The image analyzer was first calibrated automatically to convert the measurement units (pixels) produced by image analyzer program to actual micrometer units.
From each specimen, five slides of the best prepared histological section of H\&E stains were chosen to get ten measurements of the formed dentin and then the mean values obtained.

\section{Results}

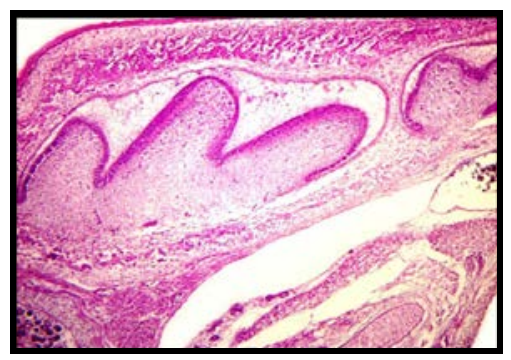

Figure 1. The tooth germ of lower first molar of albino rat at birth was at the beginning of late bell stage. Thin layer of dentin matrix appeared deposited at the cusps of (control, BD) group. Dentin matrix at the middle cusp showed greater extension along its slops. The odontoblasts were well differentiated with proximally situated nuclie and extended along the slops of all cusps. The inner enamel epithelium (IEE) appeared as continues layer of well differentiated tall columnar cells. The stellate reticulum appeared as star shaped cells few layer of flattened cells intervened between the inner enamel epithelium and stellate reticulum cells constituting the stratum intermedium. The dental papilla seamed of moderate vascularity as showed by thin wall blood vessels adjacent to the differentiating odontobalst cell layer. (H\&Ex40)

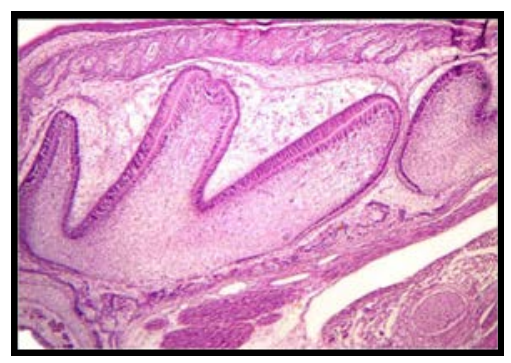

Figure 2. A marked degree of morphodifferantion of the mandibular first molars were evident, no histological evidence for the development of third molars were noticed. Increased thickness of dentin formation could be easily traced along the cusps slopes forming a continuous band of calcified tissue. The adjacent odontoblasts appeared normal, well organized and exhibited normal basal polarity of their nuclei. The inner enamel epithelium exhibited normal apical nuclei. (H\&Ex40)

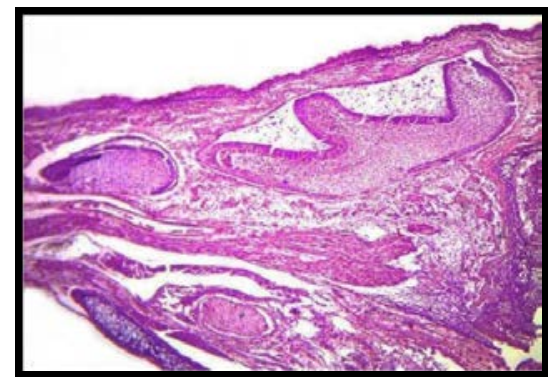

Figure 3. The histodifferatiation of the mandibular molars were not comparable to that seen in the previous groups. The inner enamel epithelium exhibited distinguished appearance. An obvious areas of discontinuation of odontoblasts alignment and areas with failed odontoblasts differentiation. Showed irregular and very limited thickness of formed dentin matrix with poor differentiation of the odontoblast cells. The odontoblasts appear disorganized, ill differentiated and poorly arranged in homogenous row. Decreased vascularity in the dental follicle and dental papilla than the previous groups were also observed. The odontoblast cells were poorly differentiated with only a small area of dentin matrix formation at the mesial cusp. (H\&Ex40) 


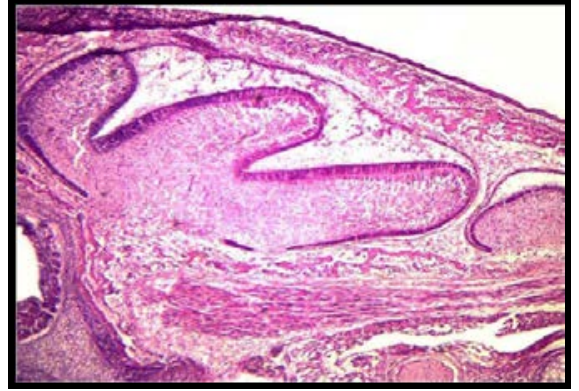

Figure 4. Advanced degree of morphodifferentiation of mandibular first molar was noticed.A thin layer of dentin matrix was formed that was continuous on all cusp slops. The adjacent odontoblastcells appeared normally aligned. (H\&Ex40)

\section{Histomorphometric Findings}

Show the comparison between the bone at birth in the different studied groups, it was found that there was a significant difference in bone in different groups except between (control, BD) and (control, FSD) group, the level of bone was higher in (control, FSD) followed by (control, $\mathrm{BD}$ ) then (diabetic, FSD) and finally (diabetic, BD) group.

The data was collected and entered into the personal computer. Statistical analysis was done using Statistical Package for Social Sciences (SPSS/ version 20) software. The statistical test used as follow; (1) Mean and standard deviation of each category. (2) Mann Whitney test was used for comparison between unpaired signed ranks test. The 5\% was chosen as the cut off level of significance.

Table 2, showed, the eruption times of the lower first molar in different studied groups, the eruption time in control group was ranged from 13-17 days with a mean of $16.08 \pm 0.90$, while in control with omega was ranged from 13-15 days with a mean of $14.0 \pm 0.85$, in diabetic group the eruption days was ranged from 16-18 days with a mean of $17.67 \pm 0.78$, finally in diabetic group with omega was ranged from 15-18 days with a mean of 16.71 \pm 1.06 , on comparing the four groups it was found that there was a significant difference between the four studied groups.

Table 2. Comparison between dentin thicknesses at birth

\begin{tabular}{|c|c|c|c|c|}
\hline & $\begin{array}{c}\text { (Control, } \\
\text { BD) }\end{array}$ & $\begin{array}{c}\text { (Control, } \\
\text { FSD) }\end{array}$ & $\begin{array}{c}\text { (Diabetic, } \\
\text { BD) }\end{array}$ & $\begin{array}{c}\text { (Diabetic, } \\
\text { FSD) }\end{array}$ \\
\hline Min. & 18254 & 22654 & 14254 & 16254 \\
\hline Max & 25654 & 31225 & 22365 & 18256 \\
\hline Mean & 21596.5 & 26031.0 & 17017.3 & 19588.0 \\
\hline S.D. & 3131.5 & 4565.3 & 3463.7 & 1155.3 \\
\hline P1 & & $0.001^{*}$ & $0.0215^{*}$ & $0.031^{*}$ \\
\hline P2 & & & $0.001^{*}$ & $0.001^{*}$ \\
\hline P3 & & & & $0.046^{*}$ \\
\hline
\end{tabular}

P1 comparison between(control, BD) and other groups.

P2 comparison between (control, FSD) group and other groups.

P3 comparison between (diabetic, BD) and (diabetic, FSD) groups

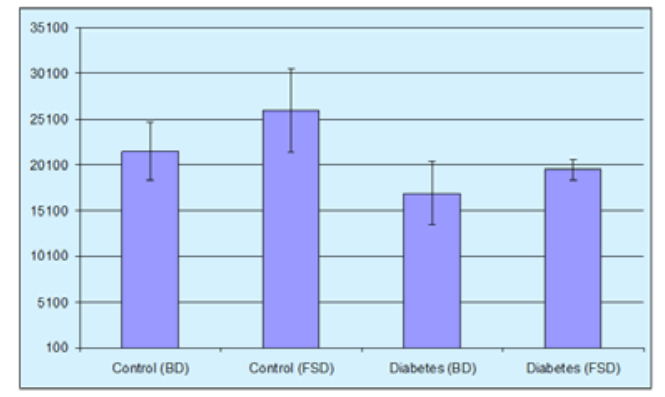

Comparison between dentin thicknesses in the different studied groups at birth

\section{Discussion}

In this study, we have examined the effect of long chain polyunsaturated fatty acids on the development of teeth of rat offspring whose mothers were Fed the special formulated flaxseed diet (FSD) during pregnancy and lactation. We focus primarily on the omega-3 fatty acids docosahexaenoic acid (DHA) and eicosapentaenoic acid (EPA), and the omega-6 fatty acid, arachidonic acid (AA).

Nutrition plays a major role in maternal and child health. Poor maternal nutritional status has been related to adverse birth outcomes; however, the association between maternal nutrition and birth outcome is complex and is influenced by many biologic, socioeconomic, and demographic factors, which vary widely in different populations. Understanding the relation between maternal nutrition and birth outcomes may provide a basis for developing nutritional interventions that will improve birth outcomes and long-term quality of life and reduce mortality, morbidity, and health-care costs. [44] The diet and body stores of essential polyunsaturated fatty acids in pregnant women need to meet the polyunsaturated fatty acid requirements of both mother and fetus, because the developing fetus depends upon maternal fatty acids and polyunsaturated fatty acids for its supply. The omega-6 and omega-3 fatty acid status of mothers has been found to decline during pregnancy, and while normalization occurs after delivery, it appears to take more than 6 months. [45] It appeared from our clinical and histological experience the Long-chain polyunsaturated fatty acids (LCPUFAs) are essential for normal tissue growth and development and also for teeth and their supporting structures. The enamel, dentin, cementum and bone in flaxseed groups were always more mature and advanced in calcification than the other experimental groups. This is actually due to the role played by the Long-chain polyunsaturated fatty acids (LCPUFAs) in the process of mineralization of these tissues. This could be attributed to the Dietary incorporation of LCPUFAs into cell membranes within the body [46].

The composition of LCPUFAs in the diet is reflected in the fatty acid composition of a variety of body tissues and fluids, including bone marrow; the periosteum (membrane surrounding long bones); bone; and red blood cell (RBC) membranes, serum, and plasma [47].

Long-chain polyunsaturated fatty acids (LCPUFAs) and lipid mediators derived from LCPUFAs have critical roles in the regulation of a variety of biological processes. They are also involved in the regulation of stem cell proliferation and differentiation, cell cycle progression, and signal transductions all which have a great effect on tissue development and maturation [46].

In the present study the histological sections at birth revealed that the tooth germs of the lower first and second molars of the flaxseed supplemented groups had advanced morphodifferentiation at the cuspal and apical regions with increased thickness of dentin formation with proper organized odontoblast cells. While, the other groups supplemented with the basal diet showed an evident delayed dentin formation compared to their control groups.

It was shown that dietary LCPUFA deficiency in animals and humans results in decreased intestinal calcium absorption, [48] reduced synthesis of bone connective tissue matrix and loss of cartilage, bone 
demineralization, [49] increased renal and arterial calcification, [50] replacement of bone with adipose tissue, [49] and severe osteoporosis. [50] People who habitually consume a high-fish (high n-3 LCPUFA) diet, such as the Japanese and Greenland Eskimos, have a very low incidence of osteoporosis. [49] These findings, explain the observations widely demonstrated in our study.

This could be explained that hard tissue formation of dentin and bone shares great similarities in their processes. Where, Formation of bone and dentin are classical examples of matrix-mediated mineralization. The mineralization process involves a sequential and localized series of events that leads to the controlled growth and formation of carbonated apatite mineral within an extracellular matrix [51].

Each mineralizing tissue provides both a structural and chemical framework, which acts as a scaffold for mineral deposition at specific sites. In bone and dentin, type I collagen is intimately associated in a well-defined manner with calcium phosphate crystals. A common feature prevalent in mineralized tissues is the presence of acidic macromolecules. Many of these macromolecules bind calcium ions and apatite and some inhibit mineral formation from spontaneously precipitating solutions. [52] Specific roles in the mineralization process have been proposed for many of these macromolecules. These include nucleation of the mineral, control of postnucleation growth, and transformation of calcium phosphate deposits to hydroxyl apatite. Bone and dentin are both mineralized connective tissues sharing the main organic matrix constituents and the mineral phase. Therefore, systemic interference with bone formation has been shown to affect dentinogenesis [53,54].

The above explanation of long chain polyunsaturated acid effect on bone tissues and based on the bone and dentin tissues similarities demonstrate well our findings.

The mother is the sole source of omega- 3 fatty acids for the fetus and exclusively breast-fed infant. Human milk contains DHA in addition to ALA and EPA. Breast-fed infants showed decreased incidence of obesity, hypertension, diabetes mellitus, and coronary heart disease in later life with subsequent higher cognitive function. [55] Breast-fed infants showed significantly lower plasma glucose levels and higher percentage of DHA and total percentages of LCPUFAs in their skeletal muscle biopsies compared with formula fed. Breast milk is rich in longchain polyunsaturated fatty acids (LCPUFAs) and brain preferentially accumulates LCPUFAs during the last trimester of pregnancy and the first few months of life. LCPUFAs suppress the production of pro-inflammatory cytokines, regulate the function of several neurotransmitters, enhance the number of insulin receptors in the brain and other tissues, and decrease insulin resistance. It is likely that inadequate breast feeding results in marginal deficiency of LCPUFAs during the critical stages of development, which can lead to insulin resistance [55].

Long chain polyunsaturated fatty acids are thought to be beneficial for a number of chronic diseases. It is thought that omega-3 and omega- 6 fatty acids may affect the development of diabetes by modulation of insulin sensitivity in phospholipid membranes. Evidence suggests that omega-6 fatty acids are generally protective for diabetes risk, [56,57,58,59] whereas the evidence for omega-3 fatty acids is mixed. Animal studies have provided a biological model of decreased insulin resistance with increased omega intake [60,61].

There is increasing evidence that DHA, can reduce body fat in humans by increasing fat oxidation and suppressing fat deposition, preventing or reducing obesity. [62] Current evidence shows the fatty acid composition of the maternal diet during pregnancy and/or lactation can play a role in determining body composition of the child [62].

Breastfed infants of mothers supplemented with omega3 PUFAs showed a significantly reduced BMI at 12 months compared to infants of non-supplemented mothers. [63] The effect has been attributed to DHA supplementation which reduced the rate of weight gain and resulted in decreased BMI in the breastfed infants at 21 months of age [64].

In diabetes, several mechanisms may contribute to weak bone formation or increase bone damage, such as increased urinary excretion coupled with lower intestinal absorption of calcium, inappropriate homeostatic response to PTH, impaired vitamin D metabolism regulation, reduced or increased insulin-like growth factor (IGF)-I concentration, the effects of the accumulation of glycation end products on bone tissue, and extra-skeletal factors due to neuropathic and microangiopathic complications [65].

Also, Several studies have demonstrated, in diabetes, an altered balance among vitamin D metabolites, showing a marked reduction of 24,25-D levels [66)] or a decreased synthesis of vitamin D-binding protein by the liver, decreased renal hydroxylase activity, and reduced vitamin D receptor concentrations [65].

\section{References}

[1] Hornstra G. Essential fatty acids in mothers and their neonates. Am J ClinNutr 2000; 71: 1262S-9S.

[2] Uauy R, Hoffman DR. Essential fat requirements of preterm infants. Am J ClinNutr 2000; 71: 245S-50S.

[3] Mina M, Kollar EJ. The induction of odontogenesis in non-dental mesenchyme combined with early murine mandibular arch epithelium. Arch Oral Biol 1987; 32: 123-7.

[4] Ten Cate AR. Oral histology: development, structure, and function. St. Louis: Mosby, 1998. p. 81-102.

[5] Lisi S, Peterkova R, Peterka M, Vonesch JL, Ruch JV. Lesot H. Tooth morphogenesis and pattern of odontablast differentiation connect. Tissue Res 2003; 44: 167-70.

[6] Imai HN, Yamashita NO, Ninomiya Y, Eto K. Contribution of early-emigrating midbrain crest cells to the dental mesenchyme of mandibular molar teeth in rat embryos. DevBiol 1996; 176: 15165.

[7] Richardson AJ. Omega-3 fatty acids in ADHD and related neurodevelopmental disorders. Int Rev Psychiatry 2006; 18: 15572.

[8] Krummel D. Nutrition in cardiovascular disease. In: Mahan LK, Escot-Sump S, (eds). Krause's food, nutrition, and diet therapy. W.B Saunder Company, 1966.

[9] Cripe S, Frederick I, Qiu C, Williams M. Risk of preterm delivery and hypertensive disorders of pregnancy in relation to maternal co-morbid mood and migraine disorders during pregnancy. Paediatric and Perinatal Epidemiology 2011; 25: 116-23.

[10] Alwan S, Reefhuis J, Rasmussen S, Friedman J. Patterns of antidepressant medication use among pregnant women in a United States population. Journal of Clinical Pharmacology 2011; 51: 264-70.

[11] Marangell L, Martinez J, Zboyan H, Chong H, Puryear L. Omega3 fatty acids for the prevention of postpartum depression: Negative data from a preliminary, open-label pilot study. Depress Anxiety 2004; 19: 20-3. 
[12] Bennett H, Einarson A, Taddio A, Koren G, Einarson T. Prevalence of depression during pregnancy: Systematic review. ObstetGynecol 2004; 103: 698-709.

[13] Grace S, Evindar A, Stewart D. The effect of postpartum depression on child cognitive development and behavior: A review and critical analysis of the literature. Arch WomensMent Health 2003; 6: 263-74.

[14] Donovan PJ. Drugs for gestational diabetes. Australian Prescriber 2010; 33: 141-4.

[15] Naylor CD, Sermer M, Chen E, Sykora K. Cesarean delivery in relation to birth weight and gestational glucose tolerance: pathophysiology or practice style? JAMA 1996; 275: 1165-70.

[16] Magee MS, Walden CE, Benedetti TJ, Knopp RH. Influence of diagnostic criteria on the incidence of gestational diabetes and perinatal morbidity. JAMA 1993; 269: 609-15.

[17] Schmidt MI, Duncan BB, Reichelt AJ, Branchtein L, Matos MC, Costa e Forti A, et al. Gestational diabetes mellitus diagnosed with a 2-h 75-g oral glucose tolerance test and adverse pregnancy outcomes. Diabetes Care 2001; 24: 1151-5.

[18] Pettitt DJ, Knowler WC. Long-term effects of the intrauterine environment, birth weight, and breast-feeding on Pima Indians. Diabetes Care 1998; 21: B138-B41.

[19] Silverman BL, Rizzo TA, Cho NH, Metzger BE. Long-term effects of the intrauterine environment. The Northwestern University Diabetes in Pregnancy Center. Diabetes Care 1998; 21: B142-B9.

[20] Dorner M, Pinget M, Brogard JM. Essential labile diabetes (in German). MMW Munch Med Wochenschr 1977; 119: 671-4.

[21] American Diabetes Association: Summary and recommendations of the First International Conference-Workshop on Gestational Diabetes Mellitus. Diabetes Care 1980; 3: 499-501.

[22] Frenkel N. Recommendations of the Second International Workshop-Conference on Gestational Diabetes. Diabetes 1985; 34: S123-S6.

[23] Metzer BD. Recommendations of the Third International Workshop-Conference on Gestational Diabetes Mellitus. Diabetes 1991; 40: S197-S201.

[24] Metzger BE, Coustan DR. Proceedings of the Fourth International Workshop-Conference on Gestational Diabetes Mellitus. Diabetes Care 1998; 21: B1-B167.

[25] Shaw JE, Sicree RA, Zimmet PZ. Global estimates of the prevalence of diabetes for 2010 and 2030. Diabetes Res ClinPract 2010; 87: 4-14.

[26] Natarajan V, Zhao Y. Regulation of COX-2 Expression and IL-6 Release by Particulate Matter in Airway Epithelial Cells. Am J Respir Cell MolBiol 2009; 40: 19-30.

[27] Swenberg JA, Calderón-Garcidueñas L Brain inflammation and Alzheimer's-like pathology in individuals exposed to severe air pollution. ToxicolPathol 2004; 32: 650-8.

[28] Dannenberg AJ, Moraitis D. Levels of Cyclooxygenase-2 Are Increased in the Oral Mucosa of Smokers: Evidence for the Role of Epidermal Growth Factor Receptor and Its Ligands. Cancer Res 2005; 65: 664-70.

[29] Hsiao LD, Yang CM Cigarette smoke extract induces COX-2 expression via a PKCalpha/c-Src/EGFR, PDGFR/PI3K/Akt/NFkappaB pathway and p300 in tracheal smooth muscle cells. Am J Physiol Lung Cell MolPhysiol 2009; 297: 892-902.

[30] 28-Bakker W, Eringa EC, Sipkema P, van Hinsbergh VW. Endothelial dysfunction and diabetes: roles of hyperglycemia, impaired insulin signaling and obesity. Cell Tissue Res., 2009; 335: 165-89.

[31] Wong MC, Chung JW, Wong TK. Effects of treatments for symptoms of painful diabetic neuropathy: systematic review. BMJ, 2007; 335: 87.

[32] Harder T, Bergmann R, Kallischnigg G, Plagemann A. Duration of breastfeeding and risk of overweight: a meta-analysis. Am J Epidemiol. 2005 Sep 1; 162: 397-403.

[33] Muhlhausler BS, Gibson RA, Makrides M. Effect of long-chain polyunsaturated fatty acid supplementation during pregnancy or lactation on infant and child body composition: a systematic review. Am J ClinNutr. 2010 Oct; 92: 857-63.

[34] Thesleff I, Mikkola M. The role of growth factors in tooth development, Int Rev Cytol 2002; 217: 93-135.

[35] Boulton AJ, Malik RA. Neuropathy of impaired glucose tolerance and its measurement. Diabetes Care 2010; 33: 207-9.

[36] Bronner-Fraser M. Origin and development potential of the neural crest. Exp Cell Res; 218: 405-17.
[37] Berkovitz BKB, Holland GR, MOxam BJ. Oral anatomy, histology and embryuology. Early tooth development. 3rd ed. 2002. p. 290-4.

[38] Thesleff, Mikkola M. The role of growth factors in tooth development. Int Rev Cytol 2002; 217: 93-135.

[39] Thesleff, I. The genetic basis of tooth development and dental defects. Am J Med Genet A 2006; 140: 191-4.

[40] Reeves PG, Nielsen FH, Fahey GC Jr. AIN-93 purified diets for laboratory rodents: final report of the American Institute of Nutrition adhoc writing committee on the reformulation of the AIN-76A rodent diet. J Nutr. 1993; 123: 1939-1951

[41] Experimental Biology and Medicine Jianmin Chen, KahPoh Tan, Wendy E. Ward and Lilian U. Thompson. Induced Rat Mammary Tumorigenesis Exposure to Flaxseed or Its Purified Lignan during Suckling Inhibits. Experimental Biology and Medicine 2003; 228: 951-958.

[42] L M Tierney, S J McPhee, M A Papadakis. Current medical Diagnosis \& Treatment. International edition. New York: Lange Medical Books/McGraw-Hill. 2002; 1203-15.

[43] Bashkar SN. Orban oral histology and embryology-11 reduction. Mosby. St. Lais, Baltimore, Boston, Chicago, London, Philadelphia, Sydney, Torteno: 1990; 365, 339-41, 349-50, 470-3.

[44] Chen YQ, Berquin IM, Min Y, Wu R, Wu J, Perry D, et al. Modulation of prostate cancer genetic risk by omega-3 and omega-6 fatty acids. J Clin Invest 2007; 117: 1866-75.

[45] Bourre JM, Francois M, Youyou A, Dumond M, Piciotti M, Pascal G. The effects of dietary alpha-linolenic acid on the composition of nerve membranes, enzymatic activity, amplitude of electrophysiological parameters, resistance to poisons and performance of learning tasks in rats. J Nutr 1989; 119: 1880-92.

[46] Poulsen RC, Moughan PJ, Kruger MC. Long-Chain Polyunsaturated Fatty Acids and the Regulation of Bone Metabolism. ExpBiol Med (Maywood) 2007; 232: 1275-88.

[47] Watkins BA, Li Y, Seifert MF. Dietary ratio of n-6/n-3 PUFAs and docosahexaenoic acid: actions on bone mineral and serum biomarkers in ovariectomised rats. J NutrBiochem 2006; 17:282-9.

[48] Xu L, Yang Z, Jin F, Duan Y, Jin Y. Characterization of rat apical tissues in different root development stage. Connect Tissue Res 2011; 52: 393-400.

[49] Kruger MC, Schollum LM. Is docosahexaenoic acid more effective than eicosapentaenoic acid for increasing calcium bioavailability? Prostaglandins LeukotEssent Fatty Acids 2005; 73 327-34.

[50] Kesavalu L, Vasudevan B, Raghu B, Browning E, Dawson D, Novak JM, et al. Omega-3 fatty acid effect on alveolar bone loss in rats. J Dent Res 2006; 85: 648-52.

[51] Boskey AL. Matrix proteins and mineralization: an overview. Connect Tissue Res 1996; 35: 357-63.

[52] Gorski JP, Wang A, Lovitch D, Law D, Powell K, Midura RJ. Extracellular bone acidic glycoprotein-75 defines condensed mesenchyme regions to be mineralized and localizes with bone sialoprotein during intramembranous bone formation. J Biol Chem. 2004; 279: 25455-63.

[53] Wazen RM, Tye CE, Goldberg HA, Hunter GK, Smith CE, Nanci A. In vivo functional analysis of polyglutamic acid domains in recombinant bone sialoprotein. J HistochemCytochem 2007; 55: 35-42.

[54] Hao J, Zou B, Narayanan K, George A. Differential expression patterns of the dentin matrix proteins during mineralized tissue formation. Bone 2004; 34: 921-32.

[55] Das UN. The lipids that matter from infant nutrition to insulin resistance. Prostaglandins LeukotEssent Fatty Acids 2002; 67: 112.

[56] Salmeron J, Hu F, Manson J. Dietary fat intake and risk of type diabetes in women. Am J ClinNutr 2001; 73: 1019-26.

[57] Hu FB, van Dam RM, Liu S. Diet and risk of type 2 diabetes: the role of types of fat and carbohydrate. Diabetologia 2001; 4 4: 80517.

[58] Lichtenstein AH, Schwab US. Relationship of dietary fat to glucose metabolism. Atherosclerosis 2000; 150: 227-43.

[59] Vessby B, Aro A, Skarfors E, Berglund L, Salminen I, Lithell H. The risk to develop NIDDM is related to the fatty acid composition of the serum cholesterol esters. Diabetes 1994; 43: 1353-7.

[60] Storlien LH, Kraegen EW, Chisholm DJ, Ford GL, Bruce DG, Pascoe WS. Fish oil prevents insulin resistance induced by highfat feeding in rats. Science 1987; 237: 885-8. 
[61] Storlien LH, Jenkins AB, Chisholm DJ, Pascoe WS, Khouri S, Kraegen EW. Influence of dietary fat composition on development of insulin resistance in rats. Relationship to muscle triglyceride and omega-3 fatty acids in muscle phospholipid. Diabetes 1991; 40: 280-9.

[62] Oken E, Wright RO, Kleinman KP, Bellinger D, Amarasiriwardena CJ, Hu H, et al. Maternal fish consumption, hair mercury, and infant cognition in a U.S. Cohort. Environ Health Perspect 2005; 113: 1376-80.

[63] Oken E, Osterdal ML, Gillman MW, Knudsen VK, Halldorsson TI, Strom M, et al. Associations of maternal fish intake during pregnancy and breastfeeding duration with attainment of developmental milestones in early childhood: a study from the Danish National Birth Cohort. Am J ClinNutr 2008; 88: 789-96.

[64] Oken E, Radesky JS, Wright RO, Bellinger DC, Amarasiriwardena CJ, Kleinman KP, et al. Maternal fish intake during pregnancy, blood mercury levels, and child cognition at age 3 years in a US cohort. Am J Epidemiol 2008; 167: 1171-81.

[65] Carnevale V, Romagnoli E, D’Erasmo E. Skeletal involvement in patients with diabetes mellitus. Diabetes Metab Res Rev 2004; 20: 196-204.

[66] Christiansen C, Christensen MS, McNair P, Nielsen B, Madsbad S. Vitamin D metabolites in diabetic patients: decreased serum concentration of 24,25 dihydroxyvitamin D. Scandinavian Journal of Clinical and Laboratory Investigation 1982; 42 487-91. 